\title{
Avoiding Aortic Injury During Thoracentesis: A Case Report with An Emphasis on Ultrasound Guidance
}

\author{
Sultan R Alharbi* \\ Associate professor and consultant interventional radiologist, King Saud University, Saudi Arabia
}

Submission: September 13, 2021; Published: September 23, 2021

*Corresponding author: Dr. Sultan R Alharbi, Associate professor and consultant interventional radiologist, Department of Radiology and Medical imaging, College of medicine, King Saud University, P.O. Box 7805, Riyadh 11472, Kingdom of Saudi Arabia

\section{Abstract}

Percutaneous pigtail catheter thoracentesis is a common and relatively safe procedure for pleural drainage, often performed with ultrasound guidance. While injury to an intrathoracic organ is a rare and sometimes fatal complication of this procedure, ultrasound is an excellent tool for avoiding this complication and for evaluating pleural effusion. In this case report, the use of ultrasound imaging with various techniques and planes prior to and during thoracentesis is described for the identification of the thoracic aorta and for avoidance of fatal aortic injury.

Keywords: Thoracentesis; Pigtail catheter; Percutaneous; Pleural effusion; Ultrasound

\section{Introduction}

In the late 1980s, percutaneous pigtail catheters were introduced as an alternative to the more traditional larger chest tubes for pleural drainage [1]. Pigtail catheter thoracentesis has since been widely adopted for drainage of fluid, air, pus, and blood collections from the pleural space in various medical and surgical specialties [2]. Thoracentesis is a diagnostic and therapeutic procedure routinely performed for the management of pleural effusions and is typically considered a relatively safe procedure with a low risk of complications [3].

In this case report, the clinical course of elderly patient who underwent thoracentesis for pleural effusions are described to highlight the importance of using ultrasonography in identifying the thoracic aorta during left thoracenteses to avoid fatal aortic injuries. Written consent was obtained from the patient included in this case report study.

\section{Case Report}

An 85-year-old female patient with a known history of hypertension, atrial fibrillation, and stroke presented with a fever and cough. She underwent chest radiography, which showed lung infiltrates. The diagnosis of community-acquired pneumonia was made, and antibiotic treatment with azithromycin was started. After a subsequent desaturation episode, a follow-up chest radiography was performed, which showed left pleural effusion.
Ultrasound examination of the left chest was performed prior to thoracentesis using curvilinear probe. It revealed moderate left pleural effusion with a linear echogenic structure reaching the posterior chest wall likely a septation.

Left thoracentesis was planned with intention to disrupt the mentioned pleural septation for proper drainage. During the ultrasound guided thoracentesis, the echogenic linear structure was the wall of dilated aorta reaching the posterior chest wall. The diagnosis was made after using grayscale sonography transverse and longitudinal planes and pulse Doppler sonography. After that ultrasound guidance left thoracentesis performed safely without complications (Figure 1).

\section{Discussion}

Percutaneous pigtail catheter thoracentesis is a common procedure that can be performed at the bedside by pulmonologists, intensivists, and interventional radiologists under ultrasound guidance, with a low risk of complications and a high success rate $[2,4]$. The pigtail catheter can be inserted either using the Seldinger technique, which involves a combination of a needle and a wire, or using the trocar technique, which involves direct insertion of the pigtail catheter over the needle [4]. Many commercial thoracentesis kits containing all necessary items are available in the market. 


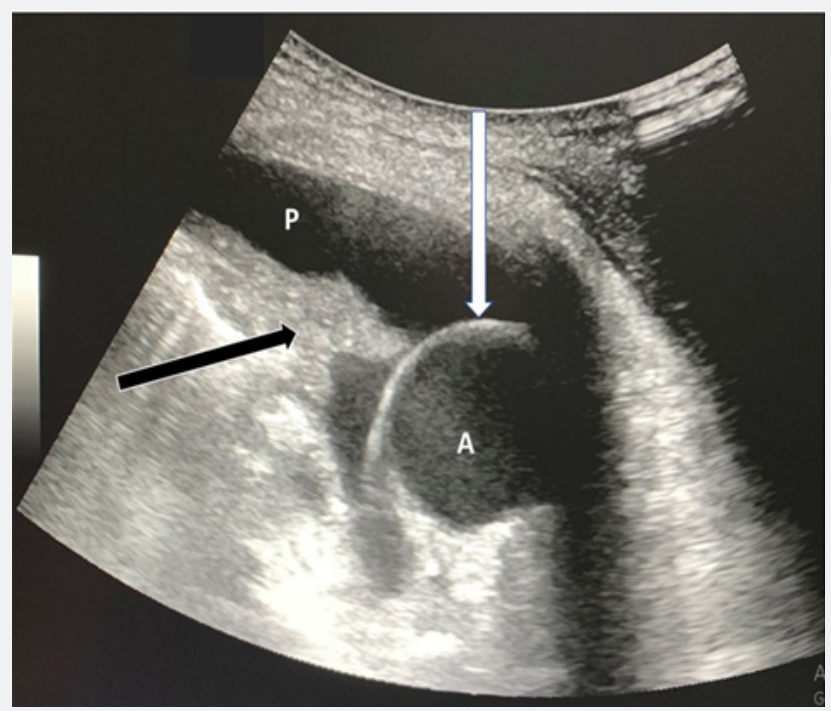

Figure 1A

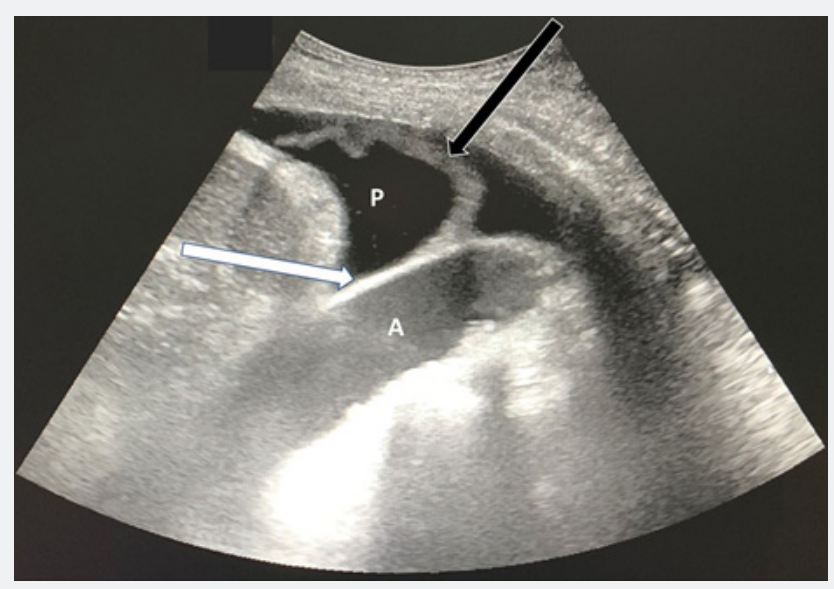

Figure 1B

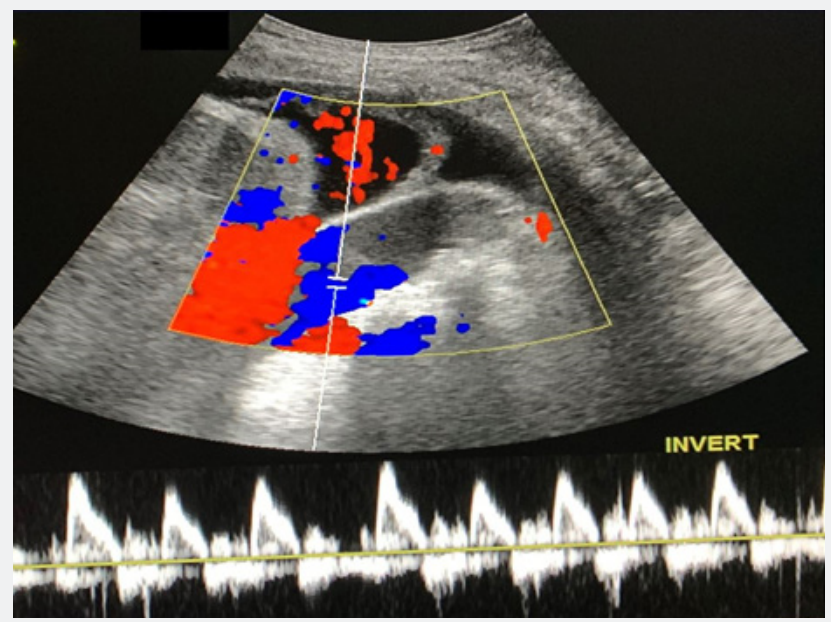

Figure 1C

Figure 1: Images from an 85-year-old woman with symptomatic left pleural effusion during thoracocentesis. Figure 1A and 1B: Grayscale sonography images of transverse and longitudinal planes of the left chest showing a dilated aorta (A), aortic wall (white arrow), pleural effusion (P), and collapsed lung (black arrow); Figure 1C: pulse Doppler imaging showing arterial waves in the thoracic aorta. 
In recent years, ultrasound guidance has increasingly been used during minimally invasive procedures in many surgical and medical specialties, including pigtail catheter thoracentesis [5]. Ultrasound has many advantages, including absence of ionizing radiation, portability, and dynamic needle visualization, which enables precise placement [3, 4]. Many reports have highlighted the decreased complication rates, lower costs, and shortened hospital stays after ultrasound-guided thoracentesis versus nonguided thoracentesis [6].

Although percutaneous thoracentesis is typically a safe procedure, incorrect placement can sometimes lead to fatal complications. Common complications of this procedure include pneumothorax, chest wall hematoma, and reexpansion of pulmonary edema. Rarer complications include iatrogenic injury to the liver, spleen, diaphragm, lung, heart, or major vessels [7]. Iatrogenic injury to the aorta is an extremely rare but fatal complication of left thoracentesis, with only a few case reports describing this complication in the literature [8].

Ultrasound is a useful imaging modality for the evaluation of pleural pathologies such as effusion. It can also be used to visualize the intercostal artery by Doppler during thoracenteses for the prevention of vascular injury [9]. The thoracic aorta, however, cannot usually be visualized via percutaneous ultrasound due to the overlying air-filled lung. In elderly patients, the aorta can also be dilated and even opposed to the posterior chest wall. Both a dilated aortic lumen and pleural effusion demonstrate fluid echogenicity, and, in such cases, the aortic wall can sometimes be mistakenly identified as a collapsed lung or a pleural effusion septation. Sonography using multiple techniques, including color and pulse Doppler, as well as using several imaging planes, can facilitate better visualization and delineation of the thoracic aorta from pleural effusion or a collapsed lung [10].

In this case report of elderly patient who underwent thoracentesis, the importance of ultrasound scanning prior to and during this procedure has been highlighted for the improved identification of the thoracic aorta and avoidance of fatal aortic injuries. Although no aortic injury was encountered in our case, misinterpret aorta as part of pleural effusion or its wall as pleural septation can lead to catastrophic complication or even death.

\section{References}

1. Fuhrman BP, Landrum BG, Ferrara TB, DM Steinhorn, AP Connell, et al. (1986) Pleural drainage using modified pigtail catheters. Crit Care Med 14(6): 575-576.

2. Laws D, Neville E, Duffy J (2003) BTS guidelines for the insertion of a chest drain. Thorax 58(Suppl 2): ii53-59.

3. Cavanna L, Mordenti P, Berte R, Maria AP, Claudia B, et al. (2014) Ultrasound guidance reduces pneumothorax rate and improves safety of thoracentesis in malignant pleural effusion: report on 445 consecutive patients with advanced cancer. World J Surg Oncol 12: 139.

4. Aziz F, Penupolu S, Flores D (2012) Efficacy of percutaneous pigtail catheters for thoracostomy at bedside. J Thorac Dis 4(3): 292-295.

5. Patel PA, Ernst FR, Gunnarsson CL (2012) Ultrasonography guidance reduces complications and costs associated with thoracentesis procedures. J Clin Ultrasound 40(3): 135-141.

6. Barnes TW, Morgenthaler TI, Olson EJ, Hesley GK, Decker PA, et al. (2005) Sonographically guided thoracentesis and rate of pneumothorax. J Clin Ultrasound 33(9): 442-446.

7. Diacon AH, Brutsche MH, Soler M (2003) Accuracy of pleural puncture sites: a prospective comparison of clinical examination with ultrasound. Chest 123(2): 436-441.

8. Goltz JP, Gorski A, Bohler J, Kickuth R, Hahn D, et al. (2011) Iatrogenic perforation of the left heart during placement of a chest drain. Diagn Interv Radiol 17(3): 229-231.

9. Toktas F, Yumun G, Goncu MT, Yalçinkaya S, Yavuz S (2013) Aortic perforation following chest tube insertion: an unusual complication. Turkish Journal of Thoracic and Cardiovascular Surgery 21(3): 765-768.

10. Sabath B, Hakim R, Yung R (2017) An 87-year-old woman with pleural effusion and tortuous aorta. Chest 151(2): e21-e24.

\begin{tabular}{|l|}
\hline \multicolumn{1}{|c|}{ Your next submission with Juniper Publishers } \\
will reach you the below assets \\
- Quality Editorial service \\
- Swift Peer Review \\
- Reprints availability \\
- E-prints Service \\
- Manuscript Podcast for convenient understanding \\
- Global attainment for your research \\
- Manuscript accessibility in different formats \\
( Pdf, E-pub, Full Text, Audio) \\
- Unceasing customer service \\
Track the below URL for one-step submission \\
https://juniperpublishers.com/online-submission.php \\
\hline
\end{tabular}

